In Macpherson, F. (2018) (ed.) Sensory Substitution and Augmentation, Proceedings of the British Academy, Oxford: Oxford University Press, pp. 1 - 42.

\title{
1 Sensory Substitution and Augmentation: An Introduction
}

\section{Fiona Macpherson}

\subsection{What are sensory substitution and sensory augmentation?}

The senses are our windows on the world. They constitute the various ways that we have of perceiving the world. Vision, hearing, touch, taste, smell, proprioception, and balance, among others, are the ways that we humans, and other creatures, have of gaining empirical knowledge about the world.

Losing a sense is a terrifying prospect. Becoming blind or deaf, losing the sense of touch or taste, or any of the other senses, would cut oneself off from important and valuable features of world. The loss of certain experiences would itself be hard to come to terms with and, practically speaking, many important activities would become more difficult: negotiating one's way around the world, communicating with other people, and avoiding danger. Even the prospect of losing one's sense of smell, the sense that most people might chose to lose, if forced to chose to lose one of them, has been shown often to have dire consequences. Unlike the loss of other senses, which typically lead to temporary depression followed by a period of readjustment, the loss of smell can often lead to lasting depression. ${ }^{1}$ Lack of enjoyment of food, inability to monitor one's body odour, increased social anxiety, impaired sex-life, and the loss of the strong connection between smell and the emotions, are among the effects of losing this sense. The prospect, therefore, of being able to replace vision, hearing, smell, or any other sense, in full or in part, by exploiting another sense or senses, is an immensely attractive prospect for some-a prospect that potentially could transform for the better the lives of those who have lost a sense. This is the prospect of sensory substitution.

For those who have been born without a sense, or lost a sense very early in life, rather than late in life, the issue of whether one should provide, or try to provide, the missing sense is a complicated one. For example, some people in the Deaf community see themselves as being differently abled compared to those people born with hearing, and not as people that are impoverished and need to be 'cured'. While people who are deaf lack access to sound, they have access to something that hearing people typically do not: the rich and distinctive Deaf language and culture. They are keen to preserve this and they would not want this to be lost by giving a sense of hearing to all deaf people. ${ }^{2}$ Nonetheless, some people who have been born without a sense, or who have lost one very early in life, would like to be able to have that sense-or at least the possibility of discovering whether they would prefer a life that included having that sense. In the case of blind people, for example, the potential to be less reliant on other

\footnotetext{
${ }^{1}$ See Deems et al. (1991), Gudziol et al. (2009), and Seo et al. (2009).

${ }^{2}$ See Hyde and Power (2006).
} 
people sometimes provides a large motivating factor to gain sight. And so, at least for some people born without one of the human senses, or who lost one early, the possibility of gaining such a sense is a highly attractive prospect, in addition to it being an immensely attractive prospect for those who lose a sense later in life.

While the prospect of being able to replace a sense is potentially transformative for those who have lost a sense, it also gives rise to new and rather exciting ideas. If replacing a sense is possible, then could we extend our existing senses, or could we give ourselves whole new senses? Who hasn't thought that it would be interesting to be able to hear or smell the range of stimuli that we know that dogs can and that humans, at least without augmentation, cannot? What schoolchild hasn't thought that having X-ray vision might be fun? Perhaps having an extended sense or having a new sense could be useful in some circumstances. When one hears about the senses that some nonhuman animals have-such as electric senses or magnetic senses, senses that open up whole new possibilities for finding out about the world, navigating through it, and acting upon it-who wouldn't want to acquire such senses, even if only on a temporary basis? Sensory augmentation devices try to deliver these possibilities. $^{3}$

We can state more formally what sensory substitution and sensory augmentation amount to. In sensory substitution, one tries to replace a missing sense by delivering some or all of the information usually gathered by one sense to another sense. What counts as a missing sense in a person in this context is determined by considering the normal sensory capacities of humans. More generally, what counts as a missing sense in a creature is determined by considering the normal sensory capacities of the species of which the creature is a member. Sensory substitution has been attempted using modern technology since the 1960s, although, arguably, other more low-tech means have been around for a lot longer. For example, the use of Braille is a way to get information about words on a page to those who are blind by exploiting their sense of touch. Likewise, the use of a cane by blind people is a way of using touch to get information about obstacles in the world-obstacles that would typically be detected by sight by those that have it. Bach-y-Rita and Kercel (2003) suggest that writing itself may be considered the first sensory substitution device as it is a way of presenting information about words to vision-information that before the invention of writing was gained through hearing the spoken word. The promise of modern technology is to provide powerful tools to replace missing senses-ideally, at least, to replace a missing sense in toto, although whether that is possible is as yet unknown. The goal that falls short of the ideal is to provide as much useful information as possible-information that one normally gets through a missing sense-by means of another sense.

An extension of this idea yields sensory augmentation. Rather than replace a missing sense with another, one tries to create a novel sense or

\footnotetext{
3 Some philosophers, such as Nudds (2004) and Richardson (2013) have, in line with Aristotle, argued that there are only five senses. I reject this view and argue against it in Macpherson (2011a) and (2013).
} 
enhance an existing sense. To do this, one has to do that which one does in sensory substitution: deliver information to a subject via a sense that does not usually deliver that information. This is why sensory substitution and augmentation are closely related. As we increasingly learn of the senses of nonhumans animals, so the intriguing possibilities of senses we can imagine giving people grows. ${ }^{4}$ Among others, we can imagine having a magnetic sense that allows us to detect magnetic fields and their properties, as pigeons do and use to navigate long distances; and we can envisage having an electric sense enabling us to detect electric fields, as many fish have; or we can contemplate having echolocation, as, for example, bats have. It might also be possible to make our senses more sensitive and thus, for example, responsive to higher or lower sounds, more and more diffuse smells, larger and smaller frequencies of electromagnetic radiation, and so on. Possessing such senses might allow us to help ourselves, and each other, in ways that we could not before. For example, having the ability to detect objects in front of us in the dark-an ability that echolocation confers-might help us in various rescue situations, as might a keener sense of hearing or smell than that which we typically have.

In addition to their potential to increase the sensory abilities of people, sensory substitution and augmentation devices might also deliver enriched experiences to people in virtual reality computer simulated worlds-and in a way that could be delivered over the internet. It is very easy to transmit images and sounds to people via screens and speakers using the internet giving them visual and auditory experiences of a virtual world. By using vibromotors placed on a person's body we can also give them experiences of touch corresponding to a virtual world. But what about experiences in other sensory modalities? That is not so easy. But sensory substitution and augmentation might be able to help. Sensory substitution might allow us to get information to a person that they would normally get from modalities other than sight, hearing and touch via those modalities-modalities that it is easy to send information to over the internet. If that is right then we might be able to enrich people's online virtual experience. For example, devices have been created that use tactile stimulation on the tongue to give people information about their position with respect to gravity-in other words information about their balance-that they would normally get through their vestibular sense. ${ }^{5}$ Using such a device, one could send information about a person's orientation to gravity corresponding to the position that a person is in in a virtual world. This is just one example of many possibilities that sensory substitution and augmentation may open up.

In conclusion, it is hoped that modern sensory substitution and augmentation devices will be able to replace or expand our senses. But to what extent has this been achieved to date? To what extent are the experiences created by sensory substitution devices like the sensory experiences that we are trying to replace? To what extent can we augment people's senses providing them with new information and new experiences? The first aim of this introduction is to delve deeply into this question to discover the usefulness of these devices, to outline the different sorts of experience that might be created,

\footnotetext{
4 See, for example, Hughes (2001).

5 See Tyler et al. (2003).
} 
and what the evidence tells us about these experiences. While there are some reasons to be hopeful about the powers of sensory substitution devices, there are also reasons to wonder whether they will ever really have the practical applications that we hope they might have. The second aim is to look to see whether the study of modern sensory substitution and augmentation devices can shed light on the nature of our senses and perception in general. Much of the philosophical, psychological, and neuroscientific work that takes place concerning sensory substitution and augmentation is keenly aware of the possibility that it might help our understanding and it seeks to comprehend many different aspects of perception.

In the sections that follow, I outline the main questions and the debates about sensory substitution and augmentation devices that have arisen in the literature to date. In section two, I will describe the two most studied modern sensory substitution devices and one sensory augmentation device. This is vital to allow the reader to have a clear idea of what sensory substitution and augmentation devices are, how subjects' behaviour changes when they use them, and what subjects say about their experience. This forms part of the evidence that is used to assess how these devices work. In section three, I will discuss whether use of these devices gives rise to new sensory experiences of objects or just new judgments about objects. In section four, on the assumption that new sensory experiences are being had, I will consider what sensory modality is operativethe substituted or the substituting one, or another altogether. I will examine the evidence concerning whether the experiences had in sensory substitution are of a two- or a three-dimensional world. And I will also examine the evidence about the nature of those experiences with respect to whether colour is represented in them. In section five, I will consider whether there are any limits to what information or what experiences can be given via sensory substitution. In section six I will discuss whether the results from sensory substitution experiments can be used to support certain theories of perception at the expense of rivals, and to provide illuminating examples of distinctions that some people want to make in articulating a theory of perception. In section seven, the practical use of sensory substitution and augmentation devices will be considered. Finally, in section eight, I will provide a brief overview of the rest of the papers that this volume contains and the host of further interesting issues that the authors consider and address.

\subsection{Sensory Substitution and Augmentation Devices}

The most famous sensory substitution device is the Tactile Visual Sensory Substitution (TVSS) device, which was developed by Paul Bach-y-Rita, initially with the help of Carter Collins (Bach-y-Rita (1969)). The device tries to replace vision by exploiting the sense of touch. Subjects who use the TVSS are either blind people or sighted people who are blindfolded. The original equipment consisted of a dentist's chair adapted so that on the back of the chair was a grid of solenoid vibrators - in other words a grid of metal pins each of which is able to vibrate. A camera was mounted on the side of the dentist's chair that produced a black and white image. This image determined which of the solenoids vibrated. 
If one imagines the black and white image overlaid on top of the grid of solenoids, those solenoids that would vibrate would be those whose locus was within a white region of the image. For example, if the image consisted of black on the left-hand side and white on the right-hand side then the solenoids on the righthand side of the grid would vibrate and those on the left would not. If the image consisted of a white circular area in the middle of a black background, then a circle of solenoids in the middle of the grid would vibrate and the rest would not. More complicated patterns could be produced, limited only by the resolution of the camera image, the resolution of the grid of solenoids, and the resolution of the skin in being able to detect them.

Later, portable versions of the device were created in which a grid of vibrating pins was strapped to a subject's back or stomach, and the camera was mounted on the subject's forehead. Later still, a version was created that, instead of using vibrating solenoids on the skin, used a grid of electrodes that could carry an electrical charge (rather than vibrate) and which were placed into the mouth to rest against the tongue (Bach-y-Rita et al. (2003)). This device is called a tongue display unit (TDU).

One reason for using the TDU is that the tongue is very sensitive to touch. Different parts of the body are more or less sensitive to touch. One way that this is measured is by a two-point discrimination test, in which a series of either one or two pinpoints is placed on subjects' skin and the subjects have to report whether they felt one or two pinpoints pressing against them. (The test is carried out with the eyes closed.) The smallest distance between two pinpoints that a subject can reliably identify through touch as being two pinpoints, rather than one, is the subject's two-point threshold. In normal subjects, the two-point threshold of the back and the stomach is rather large. For example, on the back it is between 36 to $75 \mathrm{~mm}$. The fingertips are very sensitive and have a two-point threshold of $2-4 \mathrm{~mm}$. The tongue is even more sensitive at around $1 \mathrm{~mm} .{ }^{6}$ Given that we normally want the hands to be free to carry out tasks, one can appreciate why the tongue is used. It allows for a higher resolution of image to be given to a subject, compared to the back or stomach, without limiting a subject's ability to engage with the world using their hands.

In order to practice using the device, subjects were told what was in front of them, or felt what was in front of them, when they were wearing the device. The idea was to learn what tactile stimulation corresponded to what objects and properties being in front of them. The goal was to be able to subsequently identify things using only the device.

After wearing such devices and practicing with them for a few hours subjects could:

- recognise a range of common objects in front of them at a distance from their body such as a cup, a telephone, and a toy horse;

- point accurately to objects in space; and

\footnotetext{
6 See Campbell (2006: 453).
} 
- judge objects' distance and absolute size (that is their size independent of distance from the subject/camera).

In order for the practice to be successful, thereby allowing the subjects to subsequently identify things using only the device, it is often reported that the subjects had to be able to move the camera. It is certainly true that if the camera was stationary then subjects could not learn to use the device. However, it is an interesting question to what extent self-movement is necessary. For example, if the camera is moved by another person but subjects know how it was being moved-either because they are told, or they can feel the camera so they know how it is being moved-would that be sufficient to allow subjects to learn to use the device? Current evidence does not settle this question.

Subjects are also asked to report what it is like for them when they are training using the device. They say that initially they are only aware of the tactile stimulus and tactile experience that they have. However, after a great deal of practice, they report experiencing objects out in the world in front of them. This is often called "externalising" objects and properties. They do not report the tactile stimulus or a tactile experience (although they can pay attention to the tactile stimulation if they want to and come to report on a tactile experience). Moreover, subjects report their experience in quasi-visual terms, that is, using some of the language that people normally use to report their visual experience. (I will discuss this point in more detail below.)

After around thirty hours of practice with the TVSS, subjects:

- could make complex pattern discriminations;

- could recognise the faces of members of laboratory staff; and

- displayed a looming response when the camera lens was unexpectedly zoomed.

The second point is illustrated nicely by the following report that a subject gave when identifying what was in front of her while using a TVSS device: "That is Betty; she is wearing her hair down today and does not have her glasses on; her mouth is open, and she is moving her right hand from her left side to the back of her head."7

Let me explain the third point in more detail. When a camera lens is zoomed, the images it captures changes so that things in the distance appear to move forward and expand their apparent size-that is they increase the area of the image that they occupy. This makes it look as if things in the distance are rushing toward the camera. In response to this unexpected event, the subjects automatically moved their head and body backwards-and did so even if the tactile sensation that they were receiving was on their back-seemingly supporting the subjects' reports that they localised the objects that they were detecting as being in front of them in the external world, and not where the tactile sensation was.

\footnotetext{
${ }^{7}$ Bach-y-Rita (1972: 6)
} 
Another sensory substitution device that has received much attention, study, and use is the vOICe, which was developed by Peter Meijer. ${ }^{8}$ The aim is to give people vision by using the sense of hearing, and so, like the TVSS, the device is used by either blind people or sighted people who are blindfolded. This device uses a camera mounted on a subject's forehead or glasses and converts the camera image into a "soundscape". This is a sound stimulus that lasts 1 second that begins with a click to indicate the start of the period. Consider the $\mathrm{X}$-axis and $\mathrm{Y}$-axis of a camera image. The $\mathrm{X}$-axis is represented by the duration of the sound over the one second. The Y-axis is represented by the pitch of the sound. And the volume of the sound corresponds to the brightness of each pixel. This means that unlike the TVSS, which can signal only black and white, the vOICe, one can signal black and white and shades of grey in between.

Consider the image of a sloping line in figure one. This would be represented by the vOICe by a click to indicate the start of the image, and then a brief silence followed by a note of rising pitch, followed by a brief silence. And consider the image of three dots in figure two. This would be represented by a click, a brief silence, and then a brief low pitched sound followed by a brief silence, then a brief high pitched sound followed by a brief silence, and then a brief medium pitched sound again followed by a brief silence. After the onesecond duration of the soundscape, it repeats again, starting with a click. More complex images elicit more complex sounds, with highly complex sound yielding very highly complex soundscapes. However, as with the TVSS, with practice, subjects can come to recognize objects using the device, and they report visionlike experiences: reports of a stable world appearing to be in front of them.

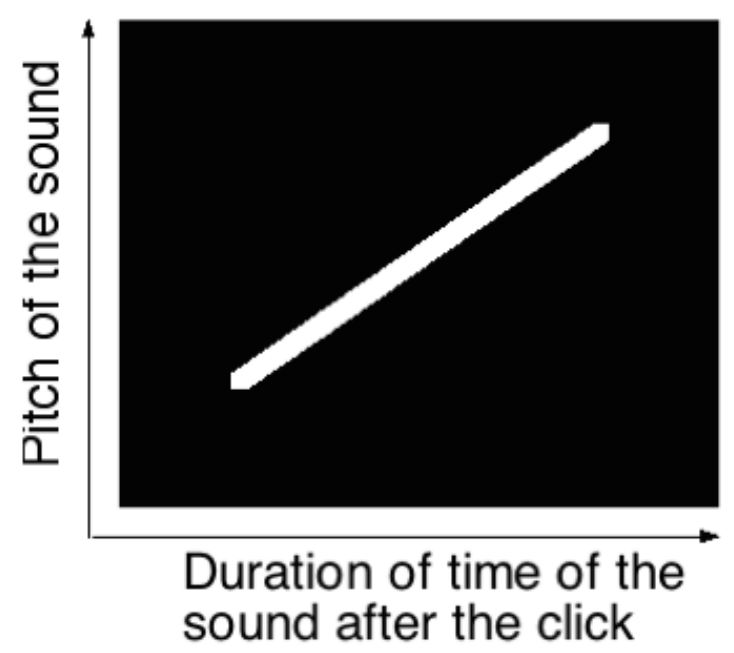

Figure 1: how a sloping line is represented by the vOICe

\footnotetext{
${ }^{8}$ See Meijer (1992). The capitalisation of "OIC" brings to mind the phrase, "Oh, I see".
} 


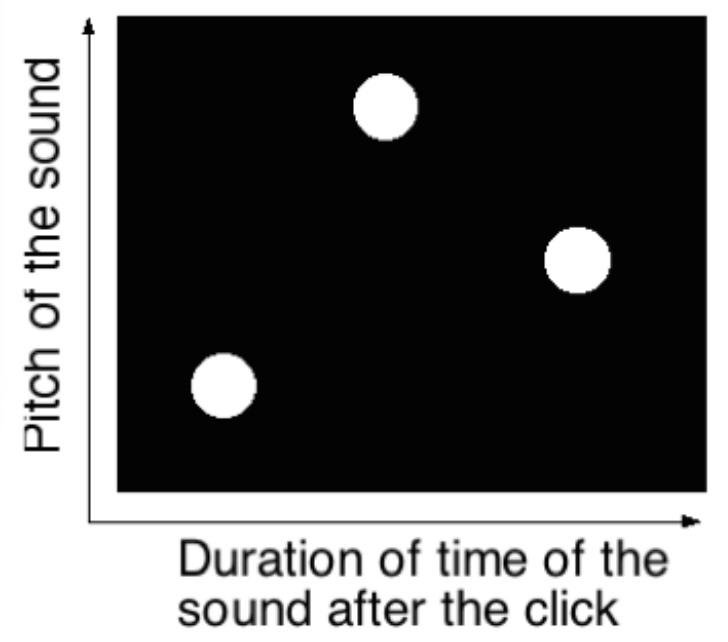

Figure 2: how three dots is represented by the vOICe

Now that I have described two of the most used and studied sensory substitution devices, I turn to describe one sensory augmentation device: the feelSpace belt. Recall that in sensory augmentation, one sense is used to try to create a new sense or enhance an existing one. The feelSpace belt, developed by Peter König, tries to give people a sense of magnetic north. The device consists of thirty vibrating actuators fitted on the inside of a belt that is worn round the waist. A compass detects magnetic north, and makes the actuator that is facing north vibrate. As the wearer moves around, the actuator that vibrates changes as the wearer's orientation towards magnetic north alters. After six weeks training consisting of wearing the belt constantly, subjects who wore the belt were better than controls at certain navigation tasks. Nagel et al. (2005) report that two out of four subjects that were trained to use the belt reported changes in their perceptual experience. They said that it was hard to describe the new experience, but that it was a sense of space different to that which they had before. They were more aware of the direction of their home or office when they were at various different locations. One subject said "reference points are intuitively present and help a lot in navigating around and understanding relations between places" (Nagel (2005: R22). This awareness was clearly distinguished from the additional tactile stimulation that the belt provided. Surprisingly, the additional spatial awareness was relative to landmarks, not to magnetic north, as the experimenters had expected.

I have now explained what sensory substitution and augmentation are, and I have explained the workings of three devices. The devices allowed discriminations of objects or directions in new ways, and in the two sensory substitution cases, subjects often reported having new experiences described in quasi-visual terms. In the sensory augmentation case two subjects reported having new experiences. In the next section, I will examine the evidence concerning whether new experiences are had and, in the section following that, I will consider whether those alleged experiences in a new modality. Subsequently, I will examine other properties of those alleged experiences. 


\subsection{Do Subjects Have a New Sensory Experience?}

In this section I will focus on what is reported to be the new "quasi-visual" experience that subjects come to have after practice with the TVSS and the vOICe. Do subjects come to have a new sensory experience, as they often report? Recall that many subjects reported a new experience of stable objects in space external to, and in front of, themselves. What is clear is that new information is getting to the subjects that allows them to do things they couldn't do before: identify and discriminate objects. But are subjects doing this because they have a new experience in addition to or instead of that experience which they had at the start of their training - an experience in addition to or instead of the tactile experience in the case of the TVSS, or the auditory experience in the case of the vOICe? The alternative to the idea that they did have a new experience is the idea the subjects just come to make new judgments or come to form new beliefs about objects that are front of themselves-judgments or beliefs that are inferred from the tactile or auditory experiences that they have at the start of their training with the sensory substitution devices and that they continue to have throughout the training.

It is very difficult, in general, to tell when a subject is having a sensory experience about something as opposed to making a judgment or having a belief about that thing. ${ }^{9}$ So even in cases of perception that do not involve sensory substitution or augmentation there are often disputes about what is, say visually experienced, and what is simply believed in response to that visual experience. One reason is that philosophers are not agreed on what objects and properties visual experience can represent, and thus on what sorts of visual experiences there are. Some philosophers think that only low-level properties such a size, shape and colour can be represented in visual experience, while others think that many other properties besides can be represented, such as natural kind properties, like being a pine-tree, or artificial kind properties, such as being a table. ${ }^{10}$ Moreover, some philosophers think that experience simply is belief or the acquisition of belief. For example, David Armstrong held that "perception is nothing but the acquiring of knowledge of, or, on occasions, the acquiring of an inclination to believe in, particular facts about the physical world, by means of our senses," (1961: 105). Along similar lines, more recently, Katherin GlüerPagin (2009) has argued that experiences are beliefs with contents of the form $x$ looks F.

In what follows, I will assume that sensory experiences are not to be equated with judgments or belief on the grounds that sensory experiences have a distinctive sort of phenomenology (by which I mean subjective character, or way that it is like, for the subject of the experience) that judging or believing lacks, and on the grounds that perceptual experiences play a different rational role, and have a different structure, from that of belief and judgment. ${ }^{11}$ And, for ease of

\footnotetext{
${ }^{9}$ See Macpherson (2012) for detailed discussion.

10 This debate is summarised in Macpherson (2011b).

${ }^{11}$ See Crane (1992) on these latter two points.
} 
exposition, I will talk as if sensory experiences can have high-level content. (Nothing turns on this. Those people who believe that experiences do not have high-level contents can simply take my descriptions of experiences with highlevel contents as specifying, in an informal manner, experiences with the sort of low-level contents that they would suppose such specifications to suggest.)

So, how can we tell whether the subjects who use the TVSS and the vOICe have new experiences about objects in the world in front of them or whether they simply make judgments about such objects based on their tactile or auditory experience? What evidence is there that can help us decide whether subjects are having new experiences?

One piece of evidence is the looming response-the automatic moving backwards away from the direction in which the camera is pointed-that TVSS subjects exhibit when the camera lens is, unbeknown to the them, zoomed in, which I mentioned in the previous section. People have been impressed with this fact, pointing out, particularly, that this effect occurs even when the tactile stimulation is on a subject's back. Subjects don't try to move away from the location of the tactile stimulation, but from the direction in which the camera is pointing, suggesting that they are experiencing objects in front of them in the direction that the camera is pointed. It is argued that the fast automatic looming response could only be driven by sensory experience of objects in front of the subject, and could not be driven by judgment, which does not occur quickly enough to drive the response. It is argued that perceptual experience occurs more quickly than judgment, which occurs as a response to, and hence at a later time than, such experience.

However, one might question the premises of this argument. Might there not be fast automatic judgment formation once subjects have practiced sufficiently using a device? Do we have really good evidence that judgment could not occur on the sort of timescale that could drive the looming response? I believe that this issue has not been investigated enough. Another concern stems from the performance of subjects in identifying objects using sensory substitution: it does not seem to be a fast automatic process at all. Most subjects have to pay great attention and be fully engaged with the task of identifying the objects in front of them in order to succeed at it. Moreover, recognition of an object in around ten seconds would be considered a good performance using a sensory substitution device. This is clearly far longer than one would take to recognise an object if one had a normal visual experience of it. One thought is that the experiences or judgments of objects' identity may take some time to have, but there may be a basic experience, an experience simply as of something being out in the world in front of them, that subjects have that precedes the experience or judgment that subjects have of objects' identity. Another thought is that subjects can make a fast automatic judgment that something is out in the world in front of them, which precedes the identification of which objects are in front of them. It is very hard to determine which is the correct account.

Another fact that some people think tells in favour of the hypothesis that subjects are having a new sensory experience is that congenitally blind people who use sensory substitution devices report that they come to have perceptual 
concepts that they did not have before-concepts such as parallax, perspective, shadow, and interposition of objects. One could try to argue that the best explanation of this new concept formation is that the congenitally blind people are having new experiences, which allows them to grasp the perceptual concepts that they did not previously.

However, one might question this conclusion on the ground that there is a good alternative explanation of what is going on that has not been ruled out. That explanation is that the congenitally blind subjects can simply form new beliefs about what is in front of them, and the relationship that those objects bear to them in egocentric space, and that it is coming to have these new beliefs that explains why they gain the new perceptual concepts. This explanation gains further support from the detailed observations of Kennedy (1993) that congenitally blind people can make and use raised-line drawings using touch, and in virtue of doing so, come to have concepts, such a perspective, that previously it was thought they could not have. This suggests that there are many ways that blind people could come to have these concepts and new visual experiences are not required.

A third piece of evidence that people have used to argue for the conclusion that subjects are having new experiences, is that one can create correlates of visual illusions using sensory substitution devices. For example, Renier et al. (2005) created a version of the Ponzo illusion using an auditoryvisual sensory substitution device. In the Ponzo illusion, two lines of equal length appear unequal when they are placed at different positions on converging lines. ${ }^{12}$ And Bach-y-Rita (1984) reports creating the waterfall illusion using the TVSS. The waterfall illusion is one in which stationary objects appear to be moving. It is caused by looking first at a constantly moving stimulus for some time before looking at stationary objects. ${ }^{13}$ How can this piece of evidence be used to argue that subjects are having new experiences? Importantly, one can get these illusions to persist, even when the subject knows conclusively that they are illusions. This is crucial because the persistence of a state that represents the world to be some way, in the face of conclusive counter evidence that they world is not that way, is one of the standard tests used to identify that a state is a perceptual experience rather than a judgment. The reason is that if one judged something to be the case, and then conclusive counter evidence was brought against that judgment, then one would expect one's judgment to change-at least it ought to change, on pain of irrationality. However, this is not the case for perceptual experiences. Illusory perceptual experiences can, and do, persist in the face of conclusive counter evidence, without one being irrational. Thus, the creation of representational states that persist despite the subject knowing that they are not veridical, and without evidence to think that they are being irrational, provides some evidence in favour of the thought that the states created are perceptual experiences and not judgments.

12 The Ponzo illusion can be seen and is discussed in this online article: Donaldson and Macpherson (July 2017).

13 The waterfall illusion can be seen online and is discussed in Macpherson and Baysan (September, 2017). 
Unfortunately, however, that evidence is not conclusive. One can defend the view that a judgment rather than a perceptual experience is being created by the use of sensory substitution devices by claiming that the judgment formed is not one that represents, say, that there are lines of unequal length in front of one-a judgment that would have to be overturned by the conclusive counter evidence that the lines were of equal length, on pain of irrationality-but a judgment, say, to the effect that there are lines that appear to be of unequal length in front of one. That judgment need not vanish in the face of conclusive counter evidence because how things are does not strictly determine how things appear. Thus, unfortunately, this alleged test for perceptual experience is not as conclusive as one would hope. Further debate on this topic would have to consider whether the notion of appearance that this defence uses can be cashed out in a way that does not make reference to perceptual experience.

One might think that one could settle the issue by scanning the brains of subjects who are using sensory substitution devices to find out whether they are having a perceptual experience-and if so in which sensory modality-or whether they are making a judgment. However doing that would have to rely on having clearly established correlations between experiences in certain modalities and their absence. But when creating experience in unusual ways, such as through substitution, it is far from clear that we know enough about such correlations to determine through scanning what is going on. For example, while people used to think that each sensory modality was associated with a different area of the cortex, increasingly, people are now doubtful whether there are any areas of the cortex that are solely correlated with one modality. ${ }^{14}$ In particular, what is called the "visual" cortex may be active whenever any spatial experience is had, rather than whenever any visual experience is had. Moreover, one also has to bear in mind that when people lose, or have never had, a particular sense then their brain develops in a nonstandard way and areas of the cortex that would otherwise have been used to process information from a particular sense may be co-opted to do other tasks, making it difficult to draw conclusions about what sort of mental state is occurring from the area of the brain that is active. For example, stimulating the "visual" cortex of early blind subjects using transcranial magnetic stimulation (TMS) during braille reading produced tactile experiences in early blind subjects, which were reported as the existence of extra dots, missing dots, or dots that did not make sense. ${ }^{15}$

One might think that the way forward is to study the detailed reports of the subjects' experience. Can we not rely on subjects' reports of their own mental states to determine whether they are having a new experience?

As I discussed earlier, many users of sensory substitution report having a distinctive new experience. But how reliable are such reports? There is no objective test to see whether a subject's report of having an experience is correct, or whether, in general, a subject is reliable in reporting his or her mental life. And even if we take the case of ordinary mundane experience that many of us

\footnotetext{
14 For example, Vetter et al. (2014) have found that they can read off "visual" cortex what auditory stimulus a subject has heard.

15 See Cohen et al. (1997).
} 
regularly have, such as our common or garden visual experience of objects in front of us had through using our eyes, there is disagreement as to what that experience is like. I have already mentioned above that there is disagreement on whether natural or artificial kinds can be represented by experience. But there are also debates about whether visual experience is of a three-dimensional world, or of a two-dimensional world with an accompanying judgment representing the third dimension - a debate that has persisted for hundreds of years. ${ }^{16}$ Another case in point is whether our visual experience is as rich as we normally take it to be. Some people think that our experience is not as detailed and highly precise as we typically take it to be, and that we do not represent colour in the periphery of our visual field. If they are right, then most of us misreport our visual experience a lot of the time. I am not here endorsing the view that experience is not as rich as we take it to be, but using the disagreement about this issue to show that there are a variety of considerations - this one being a rather radical one-that may lead us not to trust subjects' reports about their experience.

Moreover, when it comes to the experiences that are reported when subjects are using sensory substitution and augmentation devices, there is actually quite some disagreement about the nature of the experience. Recall that two out of four of the subjects that trained with the feelSpace belt said that they had new experiences of the space around them. But two of the subjects did not report that they had such new experiences. What is going on? Are two of the participants correct and two wrong? How could we tell? Or are both right: two correctly reporting that they had no new experience and two correctly reporting that they did have a new experience? Likewise, among those who report quasivisual experience when using the TVSS or the vOICe, some report that they have two-dimensional experience, and some report that they have three-dimensional experience. ${ }^{17}$ Are some of those people misreporting their experience, and if so which? Or are people just different and some have two-dimensional experience and some have three-dimensional experience?

There are numerous reasons to think that some people have a new experience and some do not-and therefore that there are simply interpersonal differences among those who use sensory substitution and augmentation devices. If that is true, there is reason to think that the different reports by the subjects reflect this fact. In other words, disparate reports do not necessarily indicate that we should not trust the reports because some are not accurate. I will now explain what reasons there are to think that there could be interpersonal differences among sensory substitution users-reasons that I think not enough people who are thinking about this issue take suitable account of, and so overlook the idea that some people may be having new experiences while other people may only be making new judgments.

The first reason is that people who use sensory substitution devices have different sorts of ability. While some people using these devices have no disability and are normally sighted (typically wearing a blindfold when using the sensory substitution device), some people are late blind, some early blind, and

\footnotetext{
16 See Smith (2000).

17 See Ward and Meijer (2010).
} 
some are congenitally blind. There is reason to think that different kinds of subjects using these devices will have different responses because their brains have developed in different ways. Second, we need to bear in mind that sensory substitution devices are different from one another. Perhaps some sensory substitution devices are more likely to give new sensory experiences than others; or some more likely to give two-dimensional experience, and some more likely to give three-dimensional experience. Third, it is also important to note the different training regimes that people have undergone when they are making their reports about their experience. Sometimes people have undergone tens of hours of practice with a device. Sometimes people have undergone hundreds of hours of practice. And in one case, a subject used a device for four years, and during two of those years they used the device constantly. Fourth, is the different level of motivation of subjects using a device. Some people are exceptionally keen to use a device and to find out what information they can get about the world using it. Some subjects become very quickly demotivated when using a device. They are disappointed that the use of the device doesn't give instant results. They are put off on account of how it feels to use the device-sometimes by how frustrating it is to learn to use it, sometimes by the lack of affect that they feel while using the device-and they therefore don't like to use it. Not surprisingly, this motivational factor might affect what happens to a subject when they use the device. For example, it may be that sustained attention and effort is required in order to come to have a new experience and that is unlikely to occur in people who are not highly motivated to practice with the device. Finally, fifth, there may just be innate differences between people that determine whether or not they have a new experience after practice with a sensory substitution or augmentation device. In short, there are many complex factors that may affect what it is like for people to use these devices, and thus what they report. Researchers should be very careful not to over-generalise and drawn conclusions about what is happening in all instances of sensory substitution and augmentation use, when their evidence base consists in just a limited range of instances of that use.

To sum up this section, showing that subjects do have a new experience, rather than come to make new judgments about the world, is a real challenge. There are no straightforward decisive practical tests for determining whether a mental state is a perceptual experience or a judgment. And most likely there are complex interpersonal differences that mean that we have to look carefully at the precise details of each case to try to decide what is going on in that case. We will probably have to weigh the evidence carefully in each case and decide where the balance of probability lies.

In the next section, I will suppose that (at least some) subjects using sensory substitution devices are having new experiences and I will investigate what we should think the nature of those experiences is.

\subsection{What is the Nature of the Experience Produced by Sensory Substitution?}

Let us suppose that (at least some) subjects who use sensory substitution devices for some reasonable period of time come to have new experiences. What 
are those experiences like? I will first investigate what the modality of the experience is. Second, I will investigate whether the experiences are of a twodimensional world or of a three-dimensional world. Third, I will consider whether the experiences represent colour, and if not, what that means these experiences are like.

\subsubsection{The Modality Issue}

Consider TVSS use. Are people using vision to perceive the world (that is, the substituted modality) or are they using touch (that is, the substituting modality)? And are the new experiences that some people have visual ones or tactile ones? And consider the vOICe. Are people using vision to perceive the world (that is, the substituted modality) or are they using hearing (that is, the substituting modality)? And are the new experiences visual ones or auditory ones? Or are none of these descriptions correct? In order to think about these questions we need to step back a little and consider the factors that differentiate the sensory modalities.

There are four traditional competing views about how one should individuate the senses. One view is that what determines the type of a sensory modality is the nature of the sensory organ: an eye in the case of vision; an ear in the case of hearing; skin in the case of touch; and so on. ${ }^{18} \mathrm{~A}$ second view is that what determines the identity of a sensory modality is the nature of the proximal stimulus that impacts on the sensory organ. So, for example, light in the case of vision; sound waves in a medium in the case of hearing; pressure and temperature in the case of touch; and so on. A third view is that what is important is what the experiences in a modality represent. So, for example, the shape, size, and colour of objects at a distance from the body in the case of vision; sounds or objects producing sounds, including pitch, volume, and timbre properties in the case of hearing; and the shape, size, surface texture, and temperature of objects pressing up against the body, including the pressure with which they press in the case of touch; and likewise for the other senses. The fourth traditional view is that what is important is the conscious nature of the experiences that the modality produces-which is determined by what it is like to have them (or their "phenomenal character"). The idea here is that visual experiences, auditory experiences, tactile experiences, and so on, each have a unique feel to them that determines the modality that is operative.

Many people think that the phenomenal character of an experience is to a large extent determined by what an experience represents. This is because when

\footnotetext{
${ }^{18}$ For the purposes of this essay, I will assume that touch is one modality. However, that fact has been questioned. Plato thought that what is commonly thought of as touch is really three distinct senses: a pressure, a temperature, and a pain sense, partly on the grounds that there are three very different sorts of phenomenal experience associated with each of these. Some modern scientists also believe that touch is actually three modalities but for different reasons. They have found that there are distinctive receptors that detect temperature, pressure, and painful stimuli, and that there are separate spots in the skin receptive to pressure, warmth, cold and painful stimuli. And so on these grounds they posit there are three distinct senses. See Macpherson (2011a).
} 
we describe the phenomenal character of our experience we typically do so by describing what objects and properties the experience represents. These people would consider the third and fourth criteria to be the same or to yield the same results.

While these accounts of the individuation of the senses all agree on the fact that vision, audition, touch, taste, and smell-the five Aristotelian sensesoperating normally and in normal conditions are all different from each other, they are competing theories because they yield different answers in other cases about what type a particular sense is. To explain this, I will consider what each theory says about the sense that is being used when someone uses a TVSS.

The first theory says that what is important is the nature of the sensory organ. In the TVSS, what is the sensory organ? It is tempting to think that the sensory organ is the camera that is detecting the scene in front of the subject. And it might be tempting to think that the camera is a type of eye. With those assumptions in place, this theory would yield the result that the sense being used is vision. However, one could deny that a camera is an eye-it is just a man-made camera. In that case, this theory would yield the result that the sense is a new one-one that has a camera for an organ. Alternatively, one could argue that the sensory organ is the skin, for it is the skin that is the organ of the subject that receives a stimulus. With that assumption in place, this theory would say that the sensory modality is touch. Another option would be to think of the whole TVSS system as being the sensory organ-the camera plus the vibrating pins and the subject's skin. This would mean that the sense was a new one-neither vision nor touch.

It is interesting to note that this theory does not tell us how to determine which physical object is the sensory organ, and it does not tell us how to identify what type of organ something is. The theory needs supplementing by accounts of those things in order to yield a verdict.

The second theory says that what is important is the nature of the proximal stimulus. But what is that? When considering the previous theory we noted that we could take the sensory organ to be either the camera or the skin. In using this second theory, we face a similar choice. We could take the proximal stimulus to be the light that hits the camera, or we could take it to be the pressure of the pins that touch the subjects' skin. The former would yield the verdict that the sense in operation was sight. The latter would yield the verdict that the sense in operation was touch.

Again note that this theory does not tell us how to determine what the proximal stimulus is in unusual cases. And it also does not specify what the proximal stimuli is for the normal operation of the Aristotelian senses in normal conditions. For example, is visible light-light of roughly 400-750 nanometresthe proximal stimulus of vision, or is the proximal stimulus any form of electromagnetic radiation, so that a sense that detected gamma rays, or x-rays or microwaves or radio waves would count as vision?

The third theory tells us to look to what the experiences produced by a sensory modality represent. Here one might think that we can discern a clearer 
result. Haven't we determined that the new experiences had in sensory substitution represent objects in front of the body of the subject? Do they therefore not represent that which visual experiences represent? The experiences using TVSS seem to represent more closely that which vision does, compared to any other sensory modality, and so one might conclude that the modality in operation here is vision. ${ }^{19}$ However, as I will spell out in more detail later, it is plausible to think that some or all of these experiences do not represent colour. For many people, including Aristotle, that is a defining feature of visual experience, and so they hold that if an experience does not represent colour then it cannot be visual. (I, myself, see no reason to reason to think that colour must be represented by visual experiences, as I will explain below.) What type of experiences are such experiences then? They don't seem like tactile experiences, as, unlike tactile experiences, they represent objects at a distance from the body, and they don't represent pressure or temperature. So perhaps they are a novel type of experience.

However, one might try to make a case that those experiences are tactile. Some psychologists have postulated that practice using a sensory substitution device gives one a novel experience but one that is in the substituting modality. They have suggested that learning to use a sensory substation device is a bit like learning certain language skills, such as learning to read or learning a new language. For example, Bach-y-Rita said:

The learning process may be similar to that which takes place in children with normal sensory and motor systems, or in adults learning a foreign language or Morse code, or in deaf persons learning manual communication (1984: 153).

And Jones says:

Meijer likens the process of learning to recognize sounds as shapes to acquiring a foreign language. Novices begin by mastering an elementary visual alphabet: a circle, a rectangle, a triangle, an oval. Since, generally speaking, all other shapes can be said to be combinations of these, the wearer of such a device begins to gain 'fluency' that makes recognizing whether a door is open or closed, or whether a chair is occupied, almost second nature (2004).

When one learns to read, one learns to recognize words, which one could not do before. Recognising words becomes fast and automatic, but we don't think

\footnotetext{
${ }^{19}$ In section three, I mentioned that there may be interpersonal difference between people with regard to whether they come to have new sensory experiences or whether they come to be able to make new judgments about the world. Of course it could be the case that the phenomenal character of new experiences produced by sensory substitution devices is different from subject to subject. For example, Auvry et al. (2007) asked sighted participants what it felt like to perceive with the vOICe. Some participants said that their experience was close to vision, others that it was closer to audition. And one of the participants said that her experience was visual when she was locating an object in space, and auditory when she was recognizing the shape of the object. In the text above, I focus on the reports of the subjects in TVSS case, which seem less variable. Again, note that the device used, and the amount of practice subjects have, and which task they are performing, are among three of many factors (the others of which I outlined in section three) that might affect the nature of subjects' mental states when using a sensory substitution device. Therefore, there may again be large interpersonal differences between people when using sensory substitution devices.
} 
that people are having nonvisual experiences when they are reading. It seems that they come to have a new type of visual experience that allows them to recognize new things. Perhaps this is a good analogy for what goes on in those who practice a lot with the TVSS. They are having new tactile experiences that allow them to recognize objects at a distance from their body which they could not do before.

Another option is to think that the new experiences are amodal or metamodal experiences in the sense that they represent that which one might think all sensory modalities can represent: objects occupying certain portions of space. However, it is not entirely certain that every modality can represent that. Can smell, for example? Exactly what smell experiences represent is highly disputed. (See Batty (2013) for discussion of this modality.) Perhaps then they are amodal or meta-modal in the sense that at least two sensory modalities can represent those objects and properties and spatial relations. Another option is that they are experiences in a novel modality-neither vision nor touch. I favour this last option, as I will explain below.

According to the fourth theory we need to think about the phenomenal character of the experiences that are being had. Are they visual or are they tactile or neither? The same considerations as were adduced for the third theory would carry-over and apply to this theory also.

Elsewhere, (Macpherson 2011), I have argued that we do not need to choose between the four theories of how to individuate the senses. I believe that people have felt compelled to do so because they subscribe to a sparse model of the senses. That is a model according to which there are relatively few types of senses-perhaps the Aristotelian five, or perhaps those plus a few others-and that those senses are relative discrete, that is, distinctive from each other. I hold that consideration of cases such as sensory substitution, but also cases of animal senses, some of which are to some degree like ours and some of which are very unlike ours, and consideration of possible but non-actual senses, show that the senses cannot be clearly divided up into a limited number of discrete kinds. The differences between the senses amounts more to a difference of degree, rather than a difference of kind. Rather than try to pigeonhole all the senses into a small number of discrete categories, we should simply note what each sense is like in respect of each of the criteria that the four theories ask us to consider. For each of the properties that these theories claim individuate the senses, we can note, if we like, how different or similar each sense is to one of the five Aristotelian senses with respect to that property, but that is relatively unimportant. One advantage of this view is that one does not have to decide on many factors that were left unspecified by the four theories. For example, one does not need to say what an eye is, or whether the camera or the skin is the proximal stimulus. One does not need to determine whether the proximal stimulus is light or electromagnetic waves more generally, or whether it is pressure on the skin. One simply needs to record all the facts about these features of a sensory modality and where one records different facts, there one records different types of perceptual system. Thus, on my account, perception using TVSS is somewhat like normal human vision, somewhat like normal human touch, and somewhat 
unique, and thus it should count as its own distinctive sensory modality-a TVSS modality.

\subsubsection{The Two- or Three-Dimension Issue}

Another question that we can raise about new experiences that people might have when using sensory substitution devices is whether they represent two- or three-dimensional objects and space. In other words, when people using these devices make depth judgments are they doing so because they experience the third dimension or is it inferred from an experience of two dimensions?

An interesting source of evidence comes from Guarniero, a congenitally blind PhD student of Bach-y-Rita, who studied the TVSS in his doctoral thesis. He also used the TVSS for three weeks himself and wrote about his experience. He said:

Very soon ... the sensations no longer felt as if they were located on my back ...By this time objects had come to have a top and bottom; a right side and a left; but no depth-they existed in an ordered two-dimensional space, the precise location of which has not yet been determined... In order to judge distance I had to master some of the cues of monocular vision, namely familiar size and interposition. I also made use of the fact that, when things are viewed from above, those farther away appear higher in the visual field. Even when interposition was the only cue I used, the objects still appeared two-dimensional and I had to infer that one was behind the other (1974:101-4).

This is very clearly a report in favour of the two-dimensional view.

However, recounting their studies with the vOICe, Ward and Meijer report on two of their subjects:

Both CC and PF report being able to perceive depth. However, both of them report that this ability occurred after having 'flat' visual experiences of edges and shading... PF ... reports her sense of depth perception arising in a kind of Eureka moment: 'I was washing dishes ... and looked down into the sink to make sure that the water had got out and I realised "Oh! I can see down. I can see depth." And I stepped back from that sink and looked down again to make sure that I wasn't fooling myself, and I walked slowly through my house looking into the rooms and it was like incredible. I could see into the room. That flat drawing now has depth to it. I can sense it'” (2010: 496).

PF was late blind and had been using the vOICe for four years, and during two of those years she had been using it immersively.

What these results again point to is that there are probably a whole host of factors (that I outlined in section three) that may affect subjects' experience. Different subjects probably experience different things, and, indeed, the same subject may experience different things at different times. Nonetheless, the clear and well-documented reports of $\mathrm{CC}$ and $\mathrm{PF}$, which attest to gaining threedimensional perceptual experience after having had only two-dimensional perceptual experience, is rather compelling evidence that three-dimensional perception can be experienced. 


\subsubsection{The Colour Issue}

What does the evidence say about the experience of colour in the new experiences in those who use sensory substitution devices, supposing, as we did above, that they do have new experiences?

To be clear, we have to distinguish between chromatic and achromatic colour. The achromatic colours are black, white, and all the shades of grey in between. The chromatic colours are all the rest, that is, all the colours that have some hue value, such as red, green, blue, yellow, and so on. Do those who use the TVSS and the vOICe have chromatic or achromatic colour experience or no colour experience? Clearly no chromatic colour information is captured about the world or relayed to subjects using those devices. However, one might think that black and white information is given to TVSS subjects. (Recall that pins either press against the subjects or they do not, with white areas in the image driving the pins to vibrate and press against the subject and black areas causing the absence of the pin press.) And one might think that black and white and greyscale information is being given to subjects who use the vOICe. (Recall that the volume of the sound captured the lightness/darkness dimension of the components of the image.) And one might suppose that this means that subjects using a TVSS will have experience of black and white, and subjects using the vOICe will have experience of black and white and shades of grey in between. However, that supposition is too quick.

Consider that one might tell the subjects how the devices work, and which stimuli correspond to white, black, and degrees of lightness. However, one needn't do that. If one did not then subjects would not know whether pressure corresponds to white or black and whether increasing volume means increasing or decreasing lightness. In such a case, what would subjects' experience be like?

It is wise here to consider the early blind, the late blind, and the sighted separately from the congenitally blind. One might imagine that the early blind, the late blind, and the sighted might have experiences of black and white and lightness because their visual system simply assigns blackness, whiteness, and different degrees of lightness to the pressure or volume stimuli, drawing on its stored representations of those colours. Perhaps it would make little practical difference which way round the visual system assigned those colours with respect to the ability of the subjects to identify which objects were in front of them. After all, we could have built the devices differently so that pressure signalled blackness and increasing volume signalled increasing darkness, rather than the other way around. Either way, subjects would have experiences of white and black and degrees of lightness, and whether they corresponded to the image that was driving the device, or were inverted with respect to that image, need not concern us with respect to the question of whether achromatic colour is represented.

Evidence for this hypothesis comes from Ward and Meijer who report PF, a late blind subject with some residual vision, using the vOICe saying: 
Just sound?... No, it is by far more, it is sight! There IS true light perception generated by The vOICe. When I am not wearing The vOICe the light I perceive from a small slit in my left eye is a grey fog. When wearing The vOICe the image is light with all the little greys and blacks... The light generated is very white and clear then it erodes down the scale of color to the dark black (2010: 495).

However, although only achromatic colour information is delivered to subjects, this might not limit the nature of the experiences that subjects have. For example, later in her life, in a dialogue between PF and JW (one of the experimenters), PF said that colors had started to appear in her experience:

PF: ... Over time my brain seems to have ... used my memory to color everything.

JW: But if you look at someone's sweater or pants you wouldn't necessarily know the color? It could be blue or red.

PF: My brain would probably take a guess at that time. It would be greyish black. Something I know such as grass, tree bark, leaves, my mind just colors it in. (2010: 497)

This suggests that the visual systems' of people who have previously had sight, can fill in colours-be they achromatic or chromatic-based on the memory of colours, or based on pure guess work. If that is right then it is tempting to think that a congenitally blind person, who must lack such memories, would not experience this. This supposition is backed up to some degree by a study by Kupers et al. (2006) that found that blind subjects trained with a TDU reported only tactile sensations on the tongue when TMS was applied to their visual cortex, while similarly trained sighted subjects reported only phosphenes (that is, hallucinatory visual experiences of lights). This suggests that the congenitally blind do not have experiences of lightness or darkness (nor of achromatic colour) when they use the TDU. It does, however, raise an interesting question about what the experience of the congenitally blind is like when they use a sensory substitution device. Do they have vision-like experiences of objects at a distance from the body that don't involve experience of chromatic or achromatic colour?

As mentioned previously, Aristotle, and almost all philosophers since then have said that there can be no visual experience of form without colour. ${ }^{20}$ They think that we experience distal form in virtue of experiencing differences in colour. If that is right then there is a worry that if congenitally blind people are not experiencing colour then perhaps they are not experiencing distal form. Perhaps this would give us a reason to think that they are merely judging what the distal form of the objects in front of them is. While it is true that humans typically experience distal form in virtue of experiencing differences in colour, must it be the case? Is another sort of experience of distal form possible?

An interesting case to consider with respect to this question is bat echolocation. Bats send out a high frequency 'chirrup' sound and listen for how long it takes the sound to return (if indeed it does) in the form of an echo, because it bounces off objects in front of them. This allows bats to determine what objects are in front of them and how far away they are. It allows them to negotiate

20 See Macpherson (2015:115) for further details. 
through their environment skillfully and quickly, dodging obstacles such as tree branches, and catching moths in the dark. Clearly, using echo-location, bats can detect three-dimensional objects at a distance from their body. But notice that in so doing-in detecting distal form-they don't detect colour. They don't use a form of perception that is able to pick up information about colour. So what is the bats' experience like? ${ }^{21}$

One idea is that bats experience distal form by experiencing soundreflectance. If that is right then perhaps one needn't experience colour to experience distant form, but perhaps one needs to detect some quality or other. If one must experience distal form by experiencing some quality or other, what quality do congenitally blind people using the TVSS or vOICe experience?

One suggestion is that they experience distal form in virtue of experiencing light reflectance, for that is what drives the camera on the TVSS and the vOICe. However, as stated before, subjects' needn't know whether a substitution device signals white or black with pressure, or increasing lightness or darkness with volume. But more than that, they needn't know what is driving the TVSS at all. For example, we could have built a device that was not driven by light reflectance but which was driven by something else that was capable of informing subjects about what was in front of them. We could, for instance, have built a device that worked by converting sound reflectance information into tactile or auditory stimuli. Therefore, based just on the information that they receive through the sensory substitution device, it is not clear how blind subjects could be experiencing distal form in virtue of experiencing light reflectance for they, or their brains, may have no idea about what is driving the system that they are interacting with.

Are there any other properties in virtue of which the congenitally blind might be experiencing distal form? The only other suggestion that I can think of is that they are experiencing distal form in virtue of experiencing the pressure that they feel on their skin in the case of the TVSS or in virtue of the sound properties that they hear in the case of the vOICe. However, it is very hard to imagine how they can experience a property-form-that they experience as being some distance in front of them, in virtue of experiencing another property-pressure or sound-that they experience as being on their skin or coming through headphones. Of course, in a causal sense of "in virtue of", the subjects are experiencing distal form in virtue of experiencing the pressure on their skin or the sound from the headphones. But that is not what is at issue here. Such a causal claim is not disputed by anyone in these cases. What is at issue is whether the subjects experience the distal form as being constituted by a pressure/nonpressure boundary on their skin or a sound/non sound/or sound with a different volume coming from the headphones.

To understand what I mean here, consider a device which was such that whenever you saw green triangle, it caused you to simultaneously have an

\footnotetext{
21 Of course this question was famously asked by Nagel (1974) who thought that in principle one cannot know everything about what it is like to be a bat. However, even if that were true, it does not stop one knowing many things about what it is like to be a bat, as Akins (1993) cleverly shows.
} 
experience of a purple square. In a causal sense of "in virtue of", you experience the square in virtue of experiencing the green triangle. But in another sense of "in virtue of" you do not experience the square in virtue of experiencing the green triangle. You do not experience the square/nonsquare boundary as being constituted by the green/nongreen boundary, or the triangle/nontriangle boundary. You experience the square as being constituted by the purple/nonpurple boundary. I call the sense of "in virtue of" in which one sees the square in virtue of the purpleness, and not in virtue of the greenness or the triangularity, the "phenomenal sense" of in virtue of. I have argued elsewhere that when one experiences one property in virtue of experiencing another in the phenomenal sense then one must experience those properties as being at the same location. ${ }^{22}$ This is not what is experienced by congenitally blind subjects using the TVSS or the vOICe. The pressure or the sound is not experienced as being at the same location as the distal objects. Therefore, I believe that they are not experiencing the distal form in virtue of, in the phenomenal sense, the pressure or the sound. Thus, as there are no good candidates for being the property in virtue of which, in the phenomenal sense, subjects experience the distal form, I suggest that they experience pure distal form-that is they experience distal form without experiencing it in virtue of, in the phenomenal sense, any other property.

In Macpherson (2015), I argue that there are other interesting mental phenomena, unrelated to sensory substitution that back up the idea that one could experience distal form without experiencing it in virtue of, in the phenomenal sense, any other property. Such cases include a special case of achromatopsia, experiences of phantom contours, experiences of amodal completion, and certain forms of type two blindsight. Spelling out the details of all of these cases would take me too far from my present purposes, but the interested reader can pursue my arguments in that paper. Moreover, in that paper, I argue that even though subjects in certain cases are not having experiences of colour there is reason to still think that their experience is visual-or at least more like visual experience than experience in any other of our sensory modalities. This is because, their experience is of distal objects, it caused by the proximal stimulus of visible light, and it is caused by the operation of the eyes. Thus, unlike Aristotle and many other philosophers, I don't think that visual experiences have to be experiences of chromatic or achromatic colour. However, as I outlined in section 4.1, because I hold a very fine-grained taxonomy of the senses that takes them to differ in degree and not kind, I think that TVSS perception and vOICe perception are different from any of our senses and so count as sui generis ways of perceiving the world, and hence as being senses distinct from vision, hearing, or any of the senses that humans have without technological intervention.

However, in whichever modality one believes the experiences of congenitally blind subjects using the TVSS or the vOICe to be in, I see no good reason to think that the fact that they do not experience colour justifies thinking that they cannot be having perceptual experience at all and must, instead, be simply making judgments about the objects in the world in front of them.

22 See Macpherson (2015). 


\subsection{What are the Limits of Sensory Substitution?}

Thus far, I have discussed the TVSS and the vOICe. These are sensory substitution systems that convey the shape, size and location of objects in space. There are variants of these devices that substitute for these properties too. I have also discussed the feelSpace belt-a device that has been used to try to give people a sense of spatial direction: magnetic north. Other kinds of sensory substitution system exist that I have not yet mentioned. One kind of device tries to substitute for the orientation of a person with respect to gravity, in other words substitute for the vestibular sense. Various forms of these devices exist. Some exploit electrical stimulation on the tongue as the substituting modality (see Tyler et al. (2003)), others exploit audition (see Dozza et al. (2004)), and others still vibrotactile stimulation on the body (see Goebel et al. (2009)). It is interesting to note that in all of the devices just mentioned, all of the properties that are being substituted are "common sensibles".

Aristotle divided up properties into proper sensibles and common sensibles. Proper sensibles are properties that are only detected through one sensory modality. For example, Aristotle thought colour is only detected through vision and so is a proper sensible of vision. Pressure is only detected through touch and so it a proper sensible of that modality. Sweetness is only detected through taste and so it is a proper sensible of taste. In contrast to this, Aristotle thought that shape is a common sensible as it can be detected by more than one sense: both vision and touch. Size, position in space, and direction are also common sensibles for they are all perceivable by more than one sense.

All the properties that I have so far spoken about substituting or providing through augmentation are common sensibles. Size, shape, and location relative to the body are clearly common sensibles. When it comes to magnetic north, we don't get the direction of magnetic north as such given to us through any sense without augmentation, but all egocentric directions are available through many different senses to us, for example through hearing and touch, and many egocentric directions are available through vision. It is easy to see how one could provide information through each of those modalities about which direction was magnetic north. Thus, all the properties that we have been considering are properties that can be detected by more than one sensory modality. Given this, one might wonder whether one can only substitute for, or augment to provide, properties that are common sensibles. Or, in addition, can one substitute for proper sensibles such as taste, smell, or pitch properties?

When we substitute for spatial properties we map each spatial dimension that is being substituted onto a separate dimension created out of a set of qualities in the substituting modality. For example, in TVSS the two-dimensional camera image is mapped onto a two dimensional patch of skin. And in the vOICe the two-dimensional camera image is mapped onto the dimensions of pitch and time of occurrence after a click. In the case of the feelSpace belt information about the direction of magnetic north is mapped onto positions on the belt. 
One might think therefore that to substitute for a proper sensible, such as taste, one has to create a mapping from dimensions of taste qualities to dimensions in another modality. One problem with this approach is that it is not clear whether each of the sensory modalities has dimensions along which we can plot each experience in that modality. For example, Wilson and Stevenson (2006) suggest that, behind the difficulties of modeling olfactory quality space, is a false assumption about olfactory experience. This is the assumption that olfactory experience is analytic - that it has various, basic distinguishable components. Instead, they argue, olfactory experience is largely synthetic; that is, the various properties of the odorant stimulus produce a largely irreducible experience. As a result, Wilson and Stevenson suggest abandoning classification schemes that attempt to model olfactory properties by means of a quality space. If they are right then this would present a great problem for creating a way of substituting for the sense of smell.

Nonetheless, let's focus on a case in which we think that there are dimensions along which one can map the experiences in the modality. One could imagine the taste dimensions consisting of degrees of intensity of the basic tastes: salty, sweet, sour, bitter, umami. And one could imagine mapping these dimensions onto other sensory dimensions. For example, a degree of pressure of a stimulus on the pinky might indicate a degree of saltiness; a degree of pressure on the ring finger might indicate a degree of sweetness, and so on for each finger, and each dimension of taste. But if one hooked up a subject to such a substitution system how would they know which qualities the pressure on the fingers referred to? If a subject had never experienced those qualities before, how could experiencing pressure on their fingers give them experiences as of taste qualities? ${ }^{23}$

When subjects use the TVSS and the vOICe, we tell them what the tactile and auditory stimulation corresponded to, namely shape, size and location information, and subjects can often find out what it corresponds to by feeling the objects in front of them - thereby using an existing sense to calibrate the substituted sense. Moreover, subjects know what shape, size and location are, for, even if they had never had sight, those are properties that one can come to be aware of through other modalities.

Now consider again the hypothetical tactile-taste substitution system that I described above. While we could tell subjects using the system that pressure on their fingers referred to different levels of basic tastes, one might think that subjects who have never had a taste sensory modality would not know what the basic tastes were, for they haven't had any awareness of them. They have only had such properties described to them, and reasonably we could question whether such descriptions really gave them knowledge of what such properties

\footnotetext{
23 The astute reader will notice that the same question arose when I considered whether we could substitute for colour-a property almost universally taken to be a proper sensible: the proper sensible of vision. In that case, I noted that memory might provide one with a means to know which property the sensory substitution device was signaling. It is of some interest to note that on my view, according to which there is a sui generis TVSS modality, colour can no longer to be thought of as a proper sensible because one can experience it in the TVSS modality as well as the visual modality.
} 
are really like. ${ }^{24}$ So one might have a strong intuition that such a system would not cause experiences of taste in subjects using it. Rather, it seems more likely that subjects would just form judgments about what tastes were being indicated to be present by the system. Moreover, even if a subject had taste memory and taste imagination, and could come to remember or imagine taste automatically in response to the pressure on the fingers, an experience of the memory or imagination of taste would seem to be a very impoverished experience compared to really tasting things. It is this fact that leads many diets to come to an end!

The intuition articulated in the last paragraph was that pressure on the fingers, caused by a device that could detect tastes, together with subjects being told what the pressure on their fingers referred to, would not cause subjects to have perceptual experiences of taste. However, this view is challenged by those who hold the sensorimotor theory of perception. Hurley and Noe (2003) hold such a view and they claim that what determines whether subjects come to have experiences in the substituted modality depends on whether they can acquire and use the common laws of sensorimotor contingency that the substituted modality shares with the perception that takes place by means of the sensory substitution device. (Sensorimotor laws are the laws that describe how one's perceptual experience changes in response to the way one acts on the world.) In the case of TVSS they think that this would happen:

as you move around an object, hidden portions of its surface come into tactilevisual view, just as they would if you were seeing them. As you move closer to an object, its apparent tactile-visual size increases, just as it would if you were seeing it. As you turn to the left, objects in "view" swing to the right in your tactile-visual field, just as they would if you were seeing them. What it is like to see is similar to what it is like to perceive by TVSS because seeing and TVSSperception are similar ways of exploring the environment: they are governed by similar sensorimotor constraints, draw on similar sensorimotor skills, and are directed toward similar visual properties, including perspectivally available occlusion properties such as apparent size and shape. (Hurley and Noe 2003: 144-145)

This is an interesting suggestion about when and why one comes to experience visual-like experiences when using a TVSS. Suppose that it is true. Does this mean that one could substitute for proper sensibles such as taste and smell? The question will turn on whether there could be enough sensorimotor contingencies in common between our ordinary perception of taste and a sensory substitution system for taste, such as the one I have described. I am not convinced that there could be, nor am I convinced that there could be enough sensorimotor contingencies in common between ordinary taste and a sensory substitution system for taste that would differentiate the sensorimotor contingencies from those involved in the detection of other proper sensibles such as smell. And even if that could be guaranteed, the question of whether we should accept the sensorimotor theory of perception has not been settled, and requires further investigation.

${ }^{24}$ See Jackson (1986) for further articulation of this point. 
In short, there are intuitions on both sides concerning whether sensory substitution or augmentation of proper sensibles is possible. To mind my there is not enough evidence supporting the intuition that it is possible, hence, I would hedge my bets on the conclusion that, sensory substitution or augmentation of proper sensibles is not possible. An exception to this might be cases where memory is able to give one experiences of the properties that were being substituted, but whether memory is capable of producing the same sort of experience as perception is highly debatable.

If only the common sensibles can be substituted or augmented, at least in people who have no memory of the properties that we are trying to substitute, then this restricts sensory substitution and augmentation to, roughly, properties of the shape and location of objects. Perhaps this makes the possibilities of the types of sensory substitution and augmentation more limited than one might have hoped for. And perhaps one might feel rather disappointed at such a conclusion. However, knowledge of spatial properties is crucial for getting around the world and so they are particularly useful ones to be able to substitute in people who lack them or to augment in cases where we wish to extend the range of our sensory powers.

\subsection{Sensory Substitution and Theories of Perception}

There are many different theories of perception in philosophy and psychology. One reason that theorists have been interested in sensory substitution is that many hoped that the results from sensory substitution experiments could be used to support certain theories at the expense of rivals, and to provide illuminating examples of distinctions that some people want to make in articulating a theory of perception.

One such case is the sensory-motor theory that I have just discussed above. Hurley and Noe (2003) claim that what determines the conscious nature of an experience is the sensory-motor constraints that govern that experience. Thus they claim that if one uses a sensory substitution system, say one that substitutes for vision using touch, then if the experiences one has obey the sensory-motor constraints of vision, rather than touch, one will have experiences with visual, and not tactile, phenomenal character. And they claim, that this is so, even if the part of the brain that processes the incoming perceptual signals is the tactile cortex, rather than the visual cortex. The way that they express this last point is that in these cases there is "cortical deference", rather than "cortical dominance". The phenomenal character of the experience is not determined by where in the cortex the perceptual signal is processed or by what phenomenal character activation of that part of the cortex has produced in the past.

Many factors make it unclear whether sensory substitution experiments support the sensory-motor theory. Several of these have been discussed above about the nature and limits of the experiences that can be produced using sensory substitution. As we have seen, the evidence about what experience is produced in which circumstances is extremely messy. Different experiences are produced in different circumstances. So the evidence does not clearly tell for or 
against the theory. Second, the sensory-motor contingencies that are produced by sensory substitution are, at best, a sub-set of those produced by the normal operation of the substituted sense, so one would expect any experience to be only partially like that produced normally in the substituted modality. Further, the substituting modality still seems to be operative, and one can attend to experiences had in that modality, while using sensory substitution. So again, the phenomenal character of the experience or experiences that are had are going to be more complex than those had while using the substituted modality in normal conditions. Thus weighing up the phenomenal character of those experiences and determining whether it coincides with the relevant sensory-motor contingencies is exceptionally difficult, and to my mind, inconclusive. Finally, even if we could clearly show that sensory substitution yields experiences that are phenomenally like those had in the substituted modality, that does not alone show that the sensory-motor theory is correct. Other factors besides sensorymotor contingencies, could be the cause of those experiences. For example, part of the within-the-head functional role of the experience-specifically the effects of the state leading to the subject holding certain beliefs about the way the world is-might be responsible. In short, evidence from sensory substitution does not settle whether the sensory-motor theory is true or false.

Another debate about the nature of perception that people hoped sensory substitution might help to settle is the debate about whether perception (broadly understood) involves two distinct elements: sensation and perception (narrowly understood), and if so, what the relationship is between them.

In fact, comprehending what this distinction amounts to is difficult. Contemporary accounts of the distinction vary widely-often without the explicit realisation that there is such disparity. Matters are not helped by the fact that many philosophers and psychologists reject the distinction-in part because the distinction is unclear, in part because there are such different understandings of it, but most importantly, because many contemporary theorists think that it is impossible to identify two separate elements answering to the descriptions given of them. Goldstein and Brockmole (2017), writing in their classic text book, Sensation and Perception, do not use the term "sensation" except in brief discussions of the history of the subject, or to explain why they do not use it! They say that the book's title reflects the fact that:

[s]ensation was discussed in the early history of perceptual psychology, and courses and textbooks followed suit including sensation in their titles. But ... researchers eventually stopped using the term sensation ... [and] as far as we are concerned, everything that involves understanding how we experience the world through our senses comes under the heading of perception. ${ }^{25}$

Bearing in mind the caveats just mentioned, let me nonetheless, attempt to give an account of the distinction between sensation and perception (narrowly understood). In the most general of terms, sensation is most usually taken to refer to some basic element involved in the use of the senses or, equivalently, in perception (broadly understood), while perception (narrowly understood) refers to a more complex element. Often sensation is spoken of

25 Goldstein and Brockmole (2017: 6) 
occurring earlier than perception (narrowly understood), and often it is claimed that perception (narrowly understood) is based on sensation, with sensation coming earlier in a causal process that leads to perception (narrowly understood). However, importantly, that is not always so. Thomas Reid, who gives an early and very influential account of sensation, is most often interpreted as holding that sensation and perception involve parallel processes and that perception is immediate and not formed on the basis of sensation. ${ }^{26}$ Looking to a prominent contemporary advocate of the distinction, Nicholas Humphrey, is quite explicit in holding a similar view. For him, sensation and perception (narrowly understood) are parallel processes and perception (narrowly understood) is not based on sensation. A third account is that sensation and perception are held to occur simultaneously with sensation taken to be a pure core and hence a part of perception (narrowly understood). For example, Dretske (1969: 75, quoted in Ben-Zeev (1984)) maintains: "if one systematically strips away from a given perceptual act all the accretions due to past experience, all the collateral information, anticipations, interpretive and inferential elements, all the habitual or conditional associations, then one will be left with a "pure sensory core"-the given of sense experience." Sometimes, particularly on this latter view, it is held that we are not normally aware of our sensations but that, with training, we can become so. ${ }^{27}$

What kind of things are sensations and perception taken to be and how have various people distinguished them? Answers to these questions give rise to the different accounts of the distinction between sensation and perception (narrowly understood).

Philosophers since Aristotle's time have discussed sensation and perception. ${ }^{28}$ And they have taken sensation to be a conscious mental state, and perception (narrowly understood) either to be or to (typically) involve a different conscious mental state-a perceptual experience-or further elements of a conscious state beyond that given by sensation that together with sensation form a perceptual experience (broadly understood). In contrast to this, some psychologists take sensation and perception (narrowly understood) to be different types of physiological processing. I think that it is important to be very clear which of these one means when talking about sensation and perception.

Of course, one might think that physiological processing and mental states will line up nicely, and one might even have hopes of one day identifying them. With that in mind, one might thereby attribute to the more primitive mental states sometimes called "sensations" some of the properties that one attributes to the more primitive physiological processing sometimes called "sensations".

\footnotetext{
26 There is some dispute among scholars over this point that is nicely summarised in Nichols (2007, chapter 5). Nichols himself concludes that Reid does not think sensation is required for perception (narrowly understood). Nichols notes, as do many other scholars, that Reid was the first person to make the distinction between sensation and perception clear. Hamlyn (1961), in his excellent book length account of the history of sensation and perception argues that Reid was the first to make it clear since Aristotle. However, readers should note that, as I indicated earlier in the text, Reid's account is far from universally adopted by scholars.

27 See Clark (2007).

${ }^{28}$ See Hamlyn (1961)
} 
And one might thereby attribute to the more sophisticated mental states sometimes called "perceptual experience" some of the properties of the more sophisticated physiological processing sometimes called "perception". This is precisely what Boring (1942, chapter 1) states happened in the late nineteenth century. Sensation and perception conceived of as mental states by philosophers were synthesized with and conjoined to a conception of sensation and perception conceived of as physiological processes by psychologists. This yielded a conception of sensation and perception in which sensations and perceptions were metal states that corresponded to two different levels of processing.

However, it is clear that such an approach is controversial. Whether such identification can be made is open to debate. Moreover, such identification will not always be feasible, given that some of the accounts of the basic physiological processing said to constitute sensation is so primitive, such as the registering of light on the retina, that it would simply not be plausible to identify it with any conscious mental state. However, other accounts of the properties of sensation , considered as a physiological process, are more amenable to identification with conscious mental states, and one could apply them to both physiological processing and to mental states, as we shall see.

One important account of the distinction between sensation and perception (narrowly understood) is that sensation involves the passive reception of sensory input in the sense that it is devoid of active mental contributions such as memory, past experience, expectation, interpretation, judgment and thought. ${ }^{29}$ In the case of physiological processing, the idea is that when we see an object, such as a table-which is called the "distal stimulus" light bounces of the table and enters our eyes. The light is called the "proximal stimulus" as it is that, rather than the table, which has a direct causal impact on our body. The registering of the light and the turning of it into an electrical signal in the nerves, carried out by the transducers in the eye, is a process which some claim is such that the signal does not "display any degree of independence from the [proximal] stimulus" (Ben-Zeev 1984: 328). And this process, together with some nerve firings slightly further down the causal chain that are all also thought not to display any independence from the proximal stimulus, is sometimes called sensation. ${ }^{30}$ In contrast, perception (narrowly understood) is a process that uses active mental contributions such as memory, past experience, expectation, interpretation, judgment and thought, so as to produce something that doesn't just correspond with the proximal stimulus -in our example, the light that impacts on the retina-but, hopefully, something that corresponds to the distal object that the light bounced off-the table. We know that many different distal stimuli are compatible with the same proximal stimulus and hence, if it exists, the same sensation. On this view, the role of perception is therefore to recover the most likely distal stimulus given the sensation and background knowledge and assumptions either built into the visual system and the mind or learned by them.

\footnotetext{
${ }^{29}$ See Hamlyn (1961) and Ben-Zeev (1984).

30 See Clark (2007).
} 
One can apply this sort of idea to sensation and perception (narrowly understood) conceived of as being or involving conscious mental states. Sensation would be a mental state that is passive and devoid of active mental contributions such as memory, past experience, expectation, interpretation, judgment and thought. Perception (narrowly understood) would be, or involve, a perceptual experience that was active in the sense that it did involve such contribution. (And one may hold that perception is in is some sense based on sensation, or one may adopt an alterative account as detailed above.)

Some people will disavow this idea of sensation, as they may disavow the idea that there is any such purely passive processing or mental states. However, denying this need not lead one to deny tout court that there is sensation, because this is not the only account of the distinction between sensation and perception.

One alternative idea is that sensation is a feeling of what is going on in me-of how I am being affected by various stimuli-whereas perception is consciousness of objects and properties external to one. It is this reading that yields the conception of sensation as including pains, itches, and tickles. It is associated with the having of subjective feelings and affect. According to Hamlyn (1961:189), "while sensations may be caused by stimuli affecting our body, to have a sensation is not necessarily, or even generally, to know anything about its cause." In contrast, perception is, or involves, a mental state that represents what is happening in the world around me. The idea is that when we perceive (broadly understood), we are aware of how we are being impacted on by the world - which is to be identified with sensation-and we are aware of what the world is like-which is to be identified with perception (narrowly understood). Humphrey (1993) advocates this elucidation of the sensation/perception distinction and endorses it as the correct account of perception (broadly understood).

A third idea is that sensations have no representational content-they have no meaning or they are not about anything. ${ }^{31}$ Meaning and representation only get a grip in perception (narrowly understood). This idea of the distinction between sensation and perception (narrowly understood) is that which Thomas Reid advocated. He claimed, sensation, "hath no object distinct from the act itself". In contrast, he held that perception (narrowly understood) involved a "conception or notion of the object perceived", and a "strong and irreducible conviction and belief of its present existence. ${ }^{32}$

What is the relationship between these last two conceptions of the distinction between sensation and perception? Are they distinct? Yes. This is because it is possible to hold the latter without the former. One can hold the view that sensations represent my body and what is happening to my it-for example that the skin on my hand is being deformed or heated-and thus they are not totally lacking a representational nature.

Sometimes researchers endorse one of these three accounts of sensation and perception, sometimes they hold more than one of these to be true. Often

\footnotetext{
31 See Ben-Zeeve (1984) for a summary of the positions of those who have held this view.

${ }^{32}$ Reid (1785/1941) Essays 1 \& 2, quoted in Hamlyn (1961) p. 460.
} 
times, they are not clear enough about which account they hold. The keen reader can find an elaboration on these conceptions of sensation and perception, and a detailed account of their historical development, in Hamlyn (1961) and BenZeeve (1984).

How has sensory substitution been thought to help in deciding whether perception (broadly understood) involves both sensation and perception (narrowly understood)? Humphrey (1993) argues that in normal vision we have both visual sensations of the light at our eye, plus visual perception (narrowly understood) of distal objects such a tables and chairs. In TVSS use, he claims that we have a tactile sensation, caused by the vibrating pins on our body plus visual perception (narrowly understood) of distal objects. This, he claims, shows us that the same visual perception (narrowly understood) can be accompanied by different sensations, as well as it being the case, as is widely agreed, that, if there are sensations, the same sensation can be accompanied by different perceptions (narrowly understood). Thus, he argues that sensory substitution helps to establish that there are doubly dissociable sensational and perceptual aspects to using our senses.

In a similar vein, Ned Block (1996) argues that sensory substitution supports the idea that there is a non-representational element to perceptual experience-that he calls qualia, and that he might easily have called sensation given the third definition of sensation articulated above-that is distinct from the representational aspects of perceptual experience. As we have already reported, people using TVSS report that they can attend to the tactile stimulation on their back, although they usually do not do so; they usually attend to the objects apparently in front of them. Block says that in attending to the tactile stimulations the subjects are attending to the sensation that accompanies their visual perception of external objects. In like manner, he says that during normal perception people usually just attend to the objects and properties given to them in perception, and don't normally attend to the non-representational elements of their experience-the qualia or sensational elements-but he claims, it is possible for them to do so, and that therefore they exist, with sensory substitution providing a clear example of the different introspectible elements of perception (broadly understood).

Both of these arguments rely on the thought that the tactile element of TVSS use should be considered as being sensation, in one way or another, and the only sensational element occurring during the use of the TVSS, while the visual element should be considered to be the only perceptual (narrowly understood) element occurring during it. However, these thoughts are highly questionable. One might think that there is both tactile and visual perception taking place (which may or may not involve both sensation and perception (narrowly understood). Why think that the tactile element involves only sensation? Why not think that it involves both tactile sensation of how the pins affect my body and tactile perception of those pins, in addition to the visual perception taking place? Or why think that the tactile element isn't just perception (broadly construed) that is not composed of sensation and perception (narrowly understood)? Why think that the visual element does not involve a sensational element? Or does not involve perception (broadly 
understood) that is not composed of sensation and perception (narrowly understood)? Without answers to these questions - thus without independent arguments backing up the existence of sensation and perception (narrowly understood), and how those terms apply to what occurs in sensory substitution-the case of sensory substitution should do nothing to boost our credence in the existence of a distinction between sensation and perception (narrowly understood). The evidence from sensory substitution does not alone provide evidence for the distinction, unless already seen through the lens of a theory that endorses those notions and their appropriate application to the case of sensory substitution.

In addition, as I have taken pains to show earlier in this essay, it is not straightforward at all to conclude that there are perceptual visual experiences occurring in TVSS use, or experiences in the substituted modality in sensory substitution more generally. Indeed, why think that that TVSS involves either tactile elements or visual elements at all? One might argue, as I explored in section four, that its use constitutes a new sensory modality that is neither tactile or visual. Or one might hold that it is purely tactile, perceptually speaking, and only involves judgments that are visual-like. And, moreover, what the experiences involved are like is a matter of great dispute and may be highly variable. Thus, the messiness of the evidence concerning the conscious mental states occurring in sensory substitution also foils its use as a clear demonstration of the existence and distinction between sensation and perception (narrowly understood).

\subsection{Practical Use}

As we have seen above, there appears to be some potential for sensory substitution devices to help those who have lost a sense, and for augmentation devices to provide us with more information that we already obtain through the ordinary use of our senses. However, we have also seen some of the limitations of these devices. Many substitution devices do not give perceptual experiences that are identical to those that are missing. They perhaps give aspects of those experiences, and perhaps only in some people, and in particular conditions, and perhaps after a great deal of practice with the devices. Perhaps in some cases they do not give new experiences at all, only the ability to make judgments about the world. I also noted that many people who suffer from sensory loss (although not all) do not like using these devices and do not adopt them into their lives.

One reason that this may be so is a point that one should be clear aboutclearer about than I have been thus far. It is that the TVSS, and the vOICe, and similar devices are rather limited with respect to the types of situation in which they work. Lighting has to be bright, and the stimului have to be clearly differentiable from their background. So test stimuli are often used that consist of very dark objects on a white background or vice versa. In other words, in many instances the devices only work well in very artificial situations. Moreover, the resolution of the devices is fairly limited. The visual acuity of users of a TVSS device is very low. Sampaio et al (2001) claim that blind users averaged an acuity of only 40/860 using it. In short, people cannot use TVSS and TDU devices in 
everyday perceptual situations effectively. ${ }^{33}$ So, despite the high hopes that Bach-y-Rita had in the 1960s and 1970s that sensory substitution devices would transform the lives of those who had lost senses, sensory substitution devices are not in common use.

It remains to be seen if advances in technology will allow people to make more useful devices in the future-and at an affordable price. What I hope to have shown in this introduction is that if these practical problems can be overcome-and that is a big if-there is reason to be hopeful that some people may be able to come to have new perceptual experiences using these devices: experiences that represent some features of the world that are of practical importance to us.

\subsection{The Papers in this Volume}

The papers in this volume represent the latest psychological and philosophical thinking about the many different aspects of sensory substitution and augmentation that I have discussed above.

Renier gives a comprehensive overview of the nature of sensory substitution from a psychologist's point of view, arguing that sensory substitution devices can give people experiences in the substituted modality. Smith's responds to Renier, arguing that sensory substitution does not give someone an experience that has the phenomenal character of an experience in the substituted modality. He claims that the substituting modality takes on some of the functions of the substituted modality, making the perceptual experiences they each produce, somewhat more like each other than they would otherwise have been.

Corns' paper looks in detail at claims about the perceptual nature of sensory substitution. She differentiates the claims that sensory substitution comprises a natural modality, that it comprises a unique modality, and that it comprises a perceptual process, and she investigates closely the evidence for each claim.

Noordhof argues that in sensory substitution the substituting sense plus the sensory substitution device is not always appropriately classified as the substituted sense. He gives an alternative account according to which properties putatively proprietary to a sense modality can be presented in another modality in cases of substitution. He draws lessons for the development of any kind of representationalist or relationalist theory of phenomenal properties.

Hillenbrand et al. discuss the work of Amir Amedi's lab and investigate the nature of brain plasticity and cross-modal connections in sensory substitution, focusing on the vOICe. Brown's paper provides commentary on work from Amedi's lab. In particular he discusses the idea that sensory substitution devices may facilitate behavioural transference of skills across sense

\footnotetext{
33 See Collins (1985).
} 
modalities and that these skills are therefore amodally represented. He argues that this conclusion is not warranted from the evidence that the Amedi lab present.

Ptito et al. investigate the nature of brain plasticity and cross-modal connections in sensory substitution focusing what occurs with us of a TDU.

The paper by Proulx et al. focuses on what we can learn about spatial navigation from sensory substitution. This allows us to compare sensory substitution systems for their practical usefulness, together with their effects on the brain, and their implications for theories of cognition and cross-modal correspondences.

O'Regan defends the sensorimotor theory of perception and its account of sensory substitution. He argues that it is not plasticity which gives rise to the change of experience observed after practice with sensory substitution, but changes in the modes of interaction with the world which plasticity allows.

Briscoe is interested in whether active control of the camera is necessary for the emergence of distal attribution in TVSS. He thinks that it is but he gives an account of this fact that is at odds with that given by supporters of the sensorimotor theory of perception. He holds that the information gained by moving the camera helps to solve the causal inference problem faced by subjects' perceptual systems, namely the problem of working out what the most probable source of stimulation in the substituting modality is.

Wright and Ward define a very broad range of sensory tools, among which sensory substitution devices are just one kind. They distinguish this group of tools as ones that provide 'raw' sensory information. They differentiate these from other sensory devices that operate at a higher symbolic or conceptual level, thus providing a new taxonomy of sensory tools, and a new definition of sensory substitution.

Cohen's paper also distinguishes between sensory substitution devices that provide 'raw' sensory information-the basic form of energy to which visual receptors are normally responsive-and those that provide information about higher-level emergent features whose nature is not determined by the basic form of energy. He suggests that one could build better sensory substitution devices by building devices that provide information about such emergent features, in addition to the basic forms of energy. Cohen lays out a programmatic vision of how the design of useful sensory substitution devices should proceed.

Connolly explores ways in which the extensive literature on perceptual learning can be applied to help improve sensory substitution devices. He then use these findings to answer the question of whether the sensory experience had when using sensory substitution devices should be classified in the substituted modality, in the substituting modality, or in a new sense modality?

In contrast to Cohen and Connolly, Spence lays out a negative picture of the prospects of sensory substitution devices being able help those with sensory loss in a practical manner. He sets out fundamental and technological limitations 
of substitution devices. He also examines the negative hedonic tone that use of these devices frequently engenders.

The paper by Suarez et al. picks up on the theme established in Spence's paper about the lack of positive emotional experiences that users of sensory substitution devices often report. Suarez et al. suggest a practical way of overcoming this problem.

Lastly, Dokic also considers the emotional and hedonic experiences associated with sensory substitution. He argues that they are constituted by noetic feelings such as familiarity and presence. He explicates a view according to which neither familiarity nor presence can be reproduced in sensory substitution. However, he argues against this view drawing on the idea that such feelings can arise at the post-perceptual level, as well as at the perceptual level. He also draws on the psychological literature on metacognition, which leads him to a more optimistic view about whether positive feelings can be enjoyed by trained users of sensory substitution devices.

The depth and breadth of these papers attests to the enormous importance of sensory substitution and augmentation in thinking about the nature of perception, perceptual experience, and brain plasticity and organization, particularly cross-modal plasticity and organisation. It also attests to the interaction between perception and emotion, and the importance of the feelings that people have when using sensory substitution and augmentation devices. The potential for these devices to alter the skills and abilities that we may have through their use is as yet uncertain, yet these papers push forward our understanding of why this is so. In the end, our own ability to affect our perception through technology may prove to be the key to fully understanding its nature.

\section{References}

Akins, K. (1993) "What is it Like to Be Boring and Myopic?" inB. Dahlbom (ed.) Daniel Dennett and His Critics, Oxford: Oxford University Press, 124-60.

Armstrong, D. M. (1961) Perception and the Physical World, New York: The Humanities Press.

Auvray, M., Hanneton, S. and O’Regan, J. K. (2007) “Learning to perceive with a visuo-auditorysubstitution system: Localization and object recognition with The Voice", Perception, 36: 416-430.

Bach-y-Rita, P. (1972) Brain Mechanisms in Sensory Substitution, New York: Academic Press.

Bach-y-Rita, P. (1984) "The Relationship Between Motor Processes and Cognition in Tactile Vision Substitution", in W. Prinz and A. F. Sanders (eds.) Cognition and Motor Processes, Berlin-Heidelberg: Springer-Verlag: 150-159.

Bach-y-Rita, P. Collins, C. C., Saunders, F. A., White, B. and Scadden, L. (1969) "Vision Substitution by Tactile Image Projection", Nature, 221, 963-4.

Bach-y-Rita, P., Kaczmarek, K.A., and Tyler, M.E. (2003) “A Tongue-based Tactile Display for Portrayal of Environmental Characteristics", in L. Hettlinger 
and M. Haas, eds., Psychological Issues in the Design and Use of Virtual and Adaptive Environments, Mahwah, NJ: Lawrence Erlbaum Associates.

Bach-y-Rita, P. and Kercel, S. W. (2003) "Sensory substitution and the humanmachine interface", Trends in Cognitive Sciences, 7(12): 541-546.

Batty, C. (2013) "Smell, Philosophical Perspectives," in H. Pashler (ed.) Encyclopedia of the Mind, Thousand Oaks, CA.: Sage.

Ben-Zeev, A. (1984) "The Paassitivity Assumption of the Sensation-Perception Distinction", Brit. J. Phil. Sci., 35: 327- 343.

Block, N. (1996) "Mental Paint and Mental Latex", in E. Villanueva (ed.), Perception, (Philosophical Issues 7) Atascadero, California: Ridgeview Publishing Co.

Boring, E. G. (1942), Sensation and Perception in the History of Experimental Psychology, Oxford, England: Appleton-Century.

Campbell, W. W. (2006) DeJong's The Neurologic Examination: 6th Edition, Philadelphia: Lippincott Williams \& Wilkins.

Cohen, L.G., Celnik, P., Pascual-Leone, A., Corwell, B., Faiz, L., Dambrosia, J., Honda, M., Sadato, N., Gerloff, C., Catala, M.D. and Hallett, M. (1997) "Functional Relevance of Cross-Modal Plasticity in Blind Humans', Nature, 389: 180183.

Clark, A. (2007) "Sensory and Perceptual Consciousness", in M. Velmans and S. Schneider (eds.) The Blackwell Companion to Consciousness, 445-455.

Collins, C.C. (1985) "On mobility aids for the blind”, in Warren, D., and Strelow, E.R. (eds.). Electronic Spatial Sensing for the blind: Contributions from perception, rehabilitation, and computer vision. Dordrecht: Martinus Nijhoff Publications: 35-64.

Crane, T. (1992) “The nonconceptual content of experience”, in T. Crane (ed.),

The Contents of Experience, Cambridge: Cambridge University Press.

Deems, D.A., Doty, R.L., Settle, R.G., Moore-Gillon, V., Shaman, P., Mester, A.F. et al. (1991) "Smell and taste disorders: a study of 750 patients from the University of Pennsylvania Smell and Taste Center", Arch Otorhinolaryngol Head Neck Surg, 117: 519-528.

Donaldson, J. and Macpherson, F. (July 2017), "Ponzo Illusion" in F. Macpherson (ed.), The Illusions Index. Retrieved from http://www.illusionsindex.org/i/ponzo-illusion.

Dozza, M., Chiari L, and Horak, F. B. (2004) "A portable audio-biofeedback system to improve postural control", Conf Proc IEEE Eng Med Biol Soc, 7: 4799802.

Glüer-Pagin, K. (2009) "In Defence of a Doxastic Account of Experience", Mind \& Language 24: 297-373.

Goebel, J. A., Sinks, B. C., Parker, B. E., Richardson, N. T., Olowin, A. B. and Cholewiak, R.W. (2009). "Effectiveness of head-mounted vibrotactile stimulation in subjects with bilateral vestibular loss: a phase 1 clinical trial." Otol Neurotol, 30(2): 210-6.

Goldstein, B. and Brockmole, J. R. (2017) Sensation and Perception, $10^{\text {th }}$ edition, Boston, MA: Cengage Learning.

Guarniero, G. (1974) “Experience of tactile vision”, Perception, 3(1): 101-104. 
Gudziol, V., Wolff-Stephan, S., Aschenbrenner, K., Joraschky, P. and Hummel, T. (2009) "Depression resulting from olfactory dysfunction is associated with reduced sexual appetite-a cross-sectional cohort study", J Sex Med, 6(7): 1924-1929.

Hamlyn, D. W. (1961) Sensation and Perception: A History of the Philosophy of Perception, London: Routledge \& Kegan Paul Ltd.

Hughes, H. C. (2001) Sensory Exotica: A World Beyond Human Experience, Cambrideg MA.: MIT Press.

Humphrey, N. (1992) The History of the Mind, New York: Simon and Schuster.

Hurely, S. and Noe, A. (2003) "Neural Plasticity and Consciousness", Biology and Philosophy, 18: 131-168.

Hyde, M. and Power, D. (2006) "Some Ethical Dimensions of Cochlear Implantation for Deaf Children and Their Families", J. Deaf Stud. Deaf Educ. 11(1): 102-111.

Jackson, F., 1986, “What Mary Didn't Know”, Journal of Philosophy, 83: 291-295.

Jones, W. D. (2004) "Sight for Sore Ears: Dutchman Develops Auditory Imager for the Blind", IEEE Spectrum, $1^{\text {st }}$ February 2004, online at http://spectrum.ieee.org/biomedical/devices/sight-for-sore-ears.

Kennedy, J. M. (1993) Drawing and the Blind: Pictures to Touch, New Haven, CT: Yale University Press.

Kupers, R., Fumal, A. de Noordhout, A. M., Gjedde, A., Schoenen, J. and Ptito, M. (2006), "Transcranial magnetic stimulation of the visual cortex induces somatotopically organized qualia in blind subjects", Proc Natl Acad Sci USA.

Macpherson, F. (2011a) "Individuating the Senses", in her (ed.) The Senses: Classical and Contemporary Readings, Oxford University Press.

Macpherson, F. (2011b) "The Admissible Contents of Experience", in K. Hawley and F. Macpherson (eds.) The Admissible Contents of Experience, WileyBlackwell.

Macpherson, F. (2012) “Cognitive Penetration of Colour Experience: Rethinking the Issue in Light of an Indirect Mechanism", Philosophy and Phenomenological Research, Vol. 84 (1): 24-62.

Macpherson, F. (2013) “Can Science Tell Us That We Smell?", Mind and Language online symposium on the Brains Blog on Louise Richardson's "Flavour, Taste, and Smell" (Mind \& Language, 28(3): 322-341). http://philosophyofbrains.com/2013/06/06/louise-richardsonsynpo.aspx

Macpherson, F (2015) "The Structure of Experience, the Nature of the Visual, and Type 2 Blindsight", Consciousness and Cognition, 32:104 - 128.

Macpherson, F. and Baysan, U. (September 2017), "Waterfall Illusion" in F. Macpherson (ed.), The Illusions Index. Retrieved from http://www.illusionsindex.org/ir/waterfall-illusion.

Meijer, P. B. L. (1992) “An experimental system for auditory image representations”, IEEE Transactions on Biomedical Engineering, 39: 112121.

Nagel, S. K., Carl,C., Kringe,T., Märtin, R. and König, P. (2005) “Beyond sensory substitution-learning the sixth sense", J. Neural Eng. 2: R13-R26.

Nagel, T. (1974) "What is it Like to Be a Bat?", Philosophical Review, 83:435-50. 
Nichols, R, (2007) Thomas Reid's Theory of Perception, Oxford: Oxford University Press.

Nudds, M. (2004) “The Significance of the Senses", Proceedings of the Aristotelian Society, 104 (1): 31-51.

Reid, T. (1785/1941) Essays on the Intellectual Powers of Man, A.D. Woozely (ed.), London: Macmillan.

Renier, L., Laloyaux, C., Collignon, O., Tranduy, D., Vanlierde, A., Bruyer, R., \& De Volder, A. G. (2005) "The Ponzo illusion using auditory substitution of vision in sighted and early blind subjects", Perception, 34: 857-867.

Richardson, L. (2013) "Flavour, Taste, and Smell", Mind \& Language, 28(3): 322341).

Sampaio E., Maris S., Bach-y-Rita P. (2001) “Brain plasticity: 'visual' acuity of blind persons via the tongue", Brain Res, 908(2): 204-207.

Seo, H.S., Jeon, K.J., Hummel, T and Min, B.C. (2009) "Influences of olfactory impairment on depression, cognitive performance, and quality of life in Korean elderly", Eur Arch Otorhinolaryngol, 266(11): 1739-1745.

Smith, A. D. (2000) "Space and Sight", Mind, 109(435): 481-518.

Tyler, M., Danilov, Y. and Bach-y-Rita (2003) "Closing an Open-Loop Control System: Vestibular Substitution Through the Tongue", J. Integr. Neurosci. 02: 159.

Vetter, P., Smith, F. W., and Muckli, L. (2014) "Decoding sound and imagery content in early visual cortex", Current Biology, 24(11): 1256-1262.

Ward, J. and Meijer, P. (2010) "Visual experiences in the blind induced by an auditory sensory substitution device", Consciousness and Cognition, 19: $492-500$.

Wilson, D. A. and R. J. Stevenson, (2006) Learning to Smell: Olfactory Perception from Neurobiology to Behavior, Baltimore: Johns Hopkins University Press. 